\title{
La promotion du multilinguisme dans les politiques éducatives en Europe
}

Marion Latour

\section{OpenEdition}

1 Journals

Édition électronique

URL : http://journals.openedition.org/ries/1173

DOI : 10.4000/ries. 1173

ISSN : 2261-4265

Éditeur

Centre international d'études pédagogiques

Édition imprimée

Date de publication : 1 avril 2006

Pagination : 11-13

ISSN : 1254-4590

\section{Référence électronique}

Marion Latour, "La promotion du multilinguisme dans les politiques éducatives en Europe », Revue internationale d'éducation de Sèvres [En ligne], 41 | avril 2006, mis en ligne le 16 novembre 2011 consulté le 01 mai 2019. URL : http://journals.openedition.org/ries/1173 ; DOI : 10.4000/ries.1173

Ce document a été généré automatiquement le 1 mai 2019

(c) Tous droits réservés 


\title{
La promotion du multilinguisme dans les politiques éducatives en Europe
}

\author{
Marion Latour
}

1 Le respect de la diversité linguistique est une valeur fondamentale de l'Union européenne qui l'a inscrite dans sa Charte des droits fondamentaux (articles 21 et 22). À la Commission européenne, le multilinguisme désigne à la fois « la capacité d'une personne à utiliser plusieurs langues et la coexistence de plusieurs communautés linguistiques dans une zone géographique donnée ». En novembre 2005, la Commission a publié une communication sur ce sujet, intitulée «Un nouveau cadre stratégique pour le multilinguisme ». La sélection de sites proposée ici présente des rapports transnationaux et européens sur la politique éducative en langues.

\section{Politique de l'Union européenne en faveur du multilinguisme}

Dans sa communication sur le multilinguisme, la Commission incite les États membres à se doter d'un plan d'action national fixant des objectifs clairs pour l'enseignement des langues aux différents stades du parcours éducatif. Les autres domaines d'action qu'elle préconise sont notamment la formation des enseignants, l'apprentissage précoce des langues, l'enseignement d'une discipline par l'intégration d'une langue étrangère, un rôle accru des établissements d'enseignement supérieur et le développement du domaine d'étude du multilinguisme, avec la constitution d'un groupe d'experts indépendants http://europa.eu.int/comm

3 À l'occasion de cette communication, la Commission européenne lance un portail web sur les langues http://europa.eu.int/languages/fr/home Celui-ci permet d'accéder facilement à des informations sur les langues de l'Union européenne. Parmi les sujets traités figurent les politiques européennes au service de l'apprentissage des langues et la diversité linguistique. 
Pour situer la communication de la Commission européenne dans son contexte historique, il faut rappeler que la Commission avait adopté un premier plan d'action en juillet 2003 http://europa.eu.int/comm/index_fr.htm ${ }^{1}$ Celui-ci définissait trois priorités : étendre les avantages de l'apprentissage des langues tout au long de la vie à l'ensemble des citoyens, améliorer l'enseignement des langues et créer un environnement plus favorable aux langues. Ce plan était le résultat d'une longue concertation suite à la résolution du Parlement européen de décembre $200^{1}$ sur les langues européennes régionales ou moins répandues, qui valorisait déjà des mesures en faveur de l'apprentissage des langues et de la diversité linguistique. http://www.europarl.eu.int/

Pour répondre à la demande des chefs d'État et de gouvernement, la Commission européenne propose en août 2005 un indicateur européen des compétences linguistiques. Cet outil s'inscrit dans la série des indicateurs du processus «Éducation et formation 2010 ». La Commission propose les paramètres généraux de l'indicateur, l'approche à adopter pour le premier cycle de collecte de données et les modalités de gestion. http:// ue.eu.int/

6 Le conseil en éducation du 23 février 2006 a décidé dans un premier temps de tester les compétences en langues des élèves européens de quinze ans dans les cinq langues européennes les plus parlées : l'allemand, l'anglais, l'espagnol, le français et l'italien.

\section{Outils proposés par le Conseil de l'Europe}

$7 \quad$ Le Conseil de l'Europe est engagé depuis toujours dans la promotion du plurilinguisme. Il agit en faveur des politiques linguistiques à travers la Division des politiques linguistiques et, depuis 1994 à Graz, à travers également le Centre européen pour les langues vivantes (CELV), né d'un accord partiel élargi. Les deux outils phares du Conseil de l'Europe sont le Cadre européen commun de référence pour les langues, le CECR, et le Portfolio européen des langues. Ces deux produits sont de plus en plus employés par les décideurs des politiques linguistiques nationales et par les enseignants. http://www.coe.int ${ }^{2}$

8 En avril 2003, le Conseil de l'Europe a conçu à l'intention des responsables nationaux un Guide pour l'élaboration des politiques linguistiques éducatives en Europe, dont le sous-titre est «de la diversité linguistique à l'éducation plurilingue». Il s'agit d'un instrument d'analyse qui sert de référence à l'élaboration ou à la réorganisation de l'enseignement des langues dans les États membres. Ce document analyse les politiques linguistiques éducatives menées actuellement en Europe et expose les données nécessaires à l'élaboration et la mise en œuvre des politiques linguistiques éducatives.

Le Conseil s'est également intéressé à la promotion du bilinguisme. Il a consacré une étude intitulée «Éléments pour une politique de l'éducation bilingue » (2003), qui aborde les différents facteurs économiques, sociaux, politiques et démographiques nécessaires à la conception d'un programme bilingue. Différents modèles d'enseignement bilingue sont présentés, ainsi que des données sur l'efficacité de ce type d'enseignement, en soulignant l'importance du suivi et de l'évaluation constante des programmes.

\section{Études transnationales sur les langues en Europe}

10 La moitié de la population européenne déclare savoir parler une langue étrangère, selon l'enquête Eurobaromètre publiée en septembre 2005. Les résultats varient 
considérablement en fonction des États. Ainsi, 29 \% des Hongrois, $30 \%$ des Anglais et $36 \%$ des Portugais, Italiens et Espagnols indiquent ne maîtriser que leur propre langue, alors que $99 \%$ des Luxembourgeois sont bilingues. Selon l'enquête, l'anglais est pratiqué comme deuxième langue par un tiers de la population européenne; vient ensuite l'allemand (maîtrisé par $12 \%$ des Européens), qui devance le français (11\%) depuis l'élargissement de l'Union européenne. Le russe et l'espagnol arrivent respectivement en $4^{\mathrm{e}}$ et $5^{\mathrm{e}}$ positions. http://europa.eu.int/comm/public_opinion/index_fr.htm

11 À la demande du Haut Conseil de l'évaluation de l'école, François Grin, professeur à l'université de Genève, s'est intéressé aux enjeux de la politique linguistique: quelles langues étrangères enseigner, pour quelles raisons et compte tenu de quel contexte? Trois scénarios ont été étudiés : le «tout-à-l'anglais », le plurilinguisme et l'esperanto. Même s'il présente des risques d'instabilité et d'érosion en faveur de l'anglais, le scénario plurilingue est le plus acceptable politiquement et correspond le mieux à l'idée d'une Europe fondée sur la diversité des langues et des cultures. Il peut constituer une stratégie à long terme si des mesures d'accompagnement garantissent sa stabilité. http:// lesrapports.ladocumentationfrancaise.fr/

12 La Délégation générale à la langue française et aux langues de France, la DGLFLF, a publié en décembre 2004 une étude sur les politiques linguistiques que mènent vingt-sept pays européens pour préserver l'usage de la langue nationale sur leur territoire et pour en promouvoir l'utilisation dans les instances européennes et internationales. L'étude reprend les différentes législations applicables aux langues régionales ou aux langues des minorités nationales. http://www.culture.gouv.fr/culture/dglf/

Dans son rapport d'information sur l'enseignement des langues vivantes en France, le sénateur Jacques Legendre ${ }^{3}$ considère que l'enseignement des langues vivantes contribue au dialogue interculturel en Europe. http://www.senat.fr/

\section{NOTES}

1. Voir Revue internationale d'éducation de Sèvres, $\mathrm{n}^{\circ}$ 33, septembre 2003, pp. 107-115.

2. Voir Revue internationale d'éducation de Sèvres, $\mathrm{n}^{\circ} 33$, septembre 2003 : «L'enseignement des langues vivantes à l'étranger, enjeux et stratégies ", et en particulier pp. 95-100.

3. Voir Revue internationale d'éducation de Sèvres, n 35, avril 2004, pp. 22-23.

\section{INDEX}

Mots-clés : multilinguisme, politique éducative, politique linguistique, système éducatif Index géographique : Europe 
AUTEUR

MARION LATOUR

Documentaliste au CIEP 